\title{
COMMUNiCATION CHANNELS IN SYSTEMS FOR REMOTE MONITORING OF MINING ELECTRICAL EQUIPMENT OPERATING MODES
}

\author{
Iosiff Breido, Andrey Sichkarenko \& Yevgeniy Kotov
}
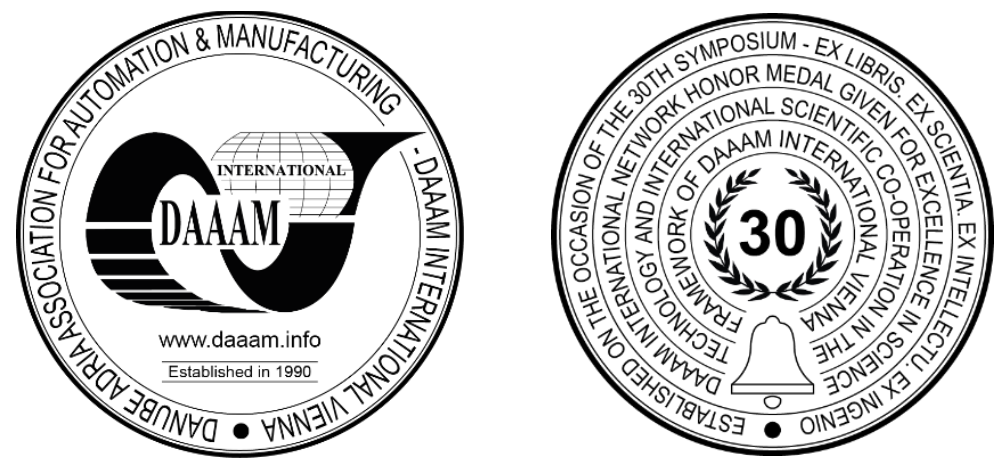

This Publication has to be referred as: Breido, I[osif]; Sichkarenko, A[ndrey] \& Kotov, Y[evgeniy] (2019). Communication Channels in Systems for Remote Monitoring of Mining Electrical Equipment Operating Modes, Proceedings of the 30th DAAAM International Symposium, pp.0298-0304, B. Katalinic (Ed.), Published by DAAAM International, ISBN 978-3-902734-22-8, ISSN 1726-9679, Vienna, Austria

DOI: $10.2507 / 30$ th.daaam.proceedings.039

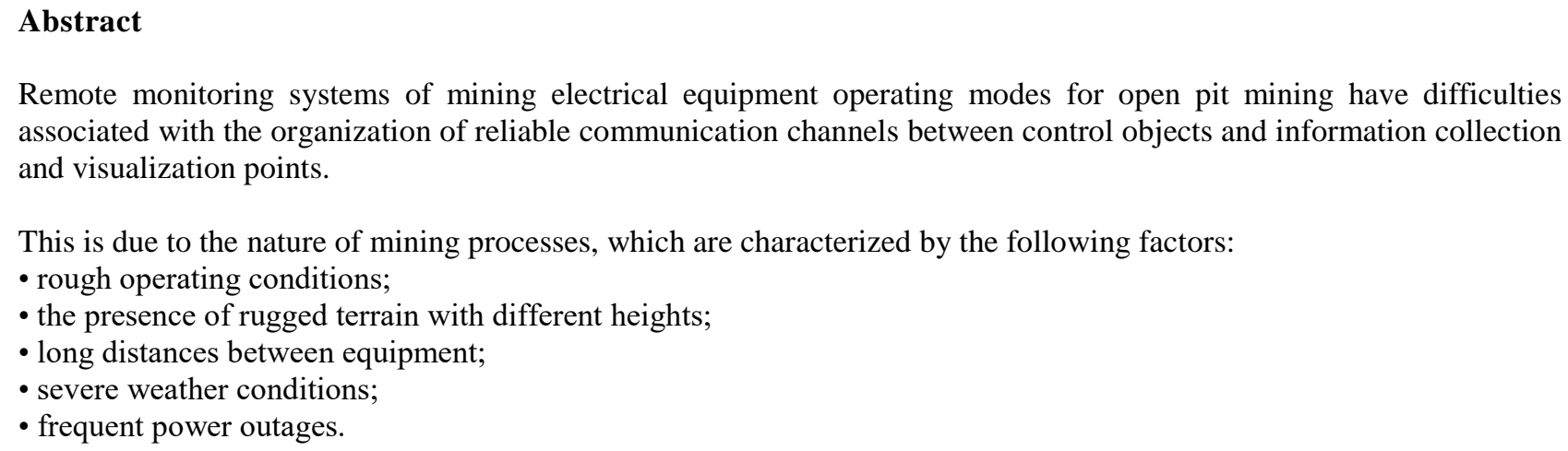

Remote monitoring systems of mining electrical equipment operating modes for open pit mining have difficulties associated with the organization of reliable communication channels between control objects and information collection and visualization points.

This is due to the nature of mining processes, which are characterized by the following factors:

- rough operating conditions;

- the presence of rugged terrain with different heights;

- long distances between equipment;

- severe weather conditions;

- frequent power outages.

These factors create the main problems in the organization of communication channels for high-quality transmission of information from source to receiver.In the paper we consider various types of communication channels used in remote monitoring systems. These are radio channels with duplication of the mobile operator, Wi-Fi and collecting information using self-organizing networks. The use of several methods of transmitting information at the same time can improve the qualitative and quantitative indicators of noise immunity and bandwidth of telemetry information transmission channels, which increases the reliability of mining electrical equipment's remote monitoring systems. The implementation of such systems provides an increase in the efficiency of the mining enterprises technological process due to the constant monitoring of electric power parameters, technological protection of substations and electric power consumption of excavators.

Keywords: Remote monitoring; mining electrical equipment; GSM; self-organizing networks; communication. 


\section{Introduction}

Open pit mining of mineral deposits is characterized by such process features as distribution of high capacity single unit equipment across long distances and its remoteness from power sources.

Mining operations stability is also greatly affected by severe operating conditions including extreme seasonal variations in temperature, various types of precipitation throughout a year, vibration, dustiness and etc. In this regard active research and pilot studies are currently in progress to work out various remote monitoring systems which allow monitoring of power consumption trends and operating conditions of electric equipment for surface and underground mining, including start-control devices, generators, electric motors, their emergency protection and control systems [1], [2], [3], [4].

This paper, based on the performed theoretical and experimental studies, presents the analysis of various data communication channels in remote monitoring systems, as well as methods to increase interference immunity in remote monitoring systems, taking into consideration mining process cycles.

\section{Characteristics of remote monitoring systems for open pit coal mines.}

Specific characteristics of remote monitoring systems are defined by the wide range of works performed by excavators, their structural features, remoteness from power sources, pit face configuration and equipment layout in the field.

Based on the existing mining technologies two levels of monitoring were offered and utilized [3]. The first level is monitoring at machine level which allows monitoring of power consumption and emergency protection of each individual excavator.

Considering that excavation cycle takes 30 seconds and based on the performed analysis and the experience in the development of remote monitoring systems the sampling interval of excavators' power consumption parameters was set for 15 seconds in order to increase interference immunity [7].

The second level is monitoring at substation level.

For power consumption accounting of each substation feeder, as well as for emergency protection tripping control and prompt emergency response purposes the sampling interval was determined based on the developed and operating remote monitoring systems for the substations at Shubarkol-Komir JSC open pit coal mine. As circular sampling is carried out at the three substations and taking into account hardware capacity and the increase of interference immunity the sampling interval was set for 10 seconds [3].

\section{The analysis of data communication channels.}

Data communication of power consumption may be done through wire and wireless means. The mostly used technologies for wired networks are RS-485 interface, current loop and PLC interface. However, this communication method cannot be used at open pit coal mines for a number of reasons. Firstly, the long distances between production equipment units and data acquisition locations (up to 10 - 15 kilometers) make cable installation impractical from both economical and technological standpoints. Secondly, there is a high probability of the communication cable getting damaged by different heavy machinery (mining dump trucks, excavators and etc.).

The use of wireless data communication technology is most appropriate for surface coal mining conditions. The choice of frequency range greatly influences the characteristics of the designed wireless network as this parameter is inextricably connected with communication distance range, bandwidth capacity, power consumption and even financial and engineering costs of the design.

Let us consider several wireless data communication methods that are technically feasible for surface coal mining conditions: the use of radio channel with $433 \mathrm{MHz}$ frequency band, the use of GSM network with $900 \mathrm{MHz}$ frequency band [5]. The structure of data communication technology and monitoring levels are presented in Figure 1 below.

One of the most practical wireless data transmission methods to identify power consumption by mining equipment is the use of radio channel with $433 \mathrm{MHz}$ frequency band. The choice of this band was done for a reason. First, $433 \mathrm{MHz}$ frequency band is not limited by the Republic of Kazakhstan law (with maximum permissible transmitter output not exceeding $10 \mathrm{~mW}$ ). Secondly, the majority of equipment uses this frequency band. General structure of this channel is shown in Figure 1-B.

This communication system has a number of advantages: data can be transferred over long distances using only permitted receiver-transmitter output; no costs associated with using GSM communication channel where payment is based on the amount of data transmitted.

However, there are some disadvantages too. In order to transmit data over long distances the units should be in line of sight from each other, but this disadvantage can be eliminated in some cases by the use of retransmitting modems.

In order to set up data communication system for mining equipment a radio modem with an appropriate antenna should be utilized. Functional diagram of data communication system using $433 \mathrm{MHz}$ radio channel is given in Figure 2. 


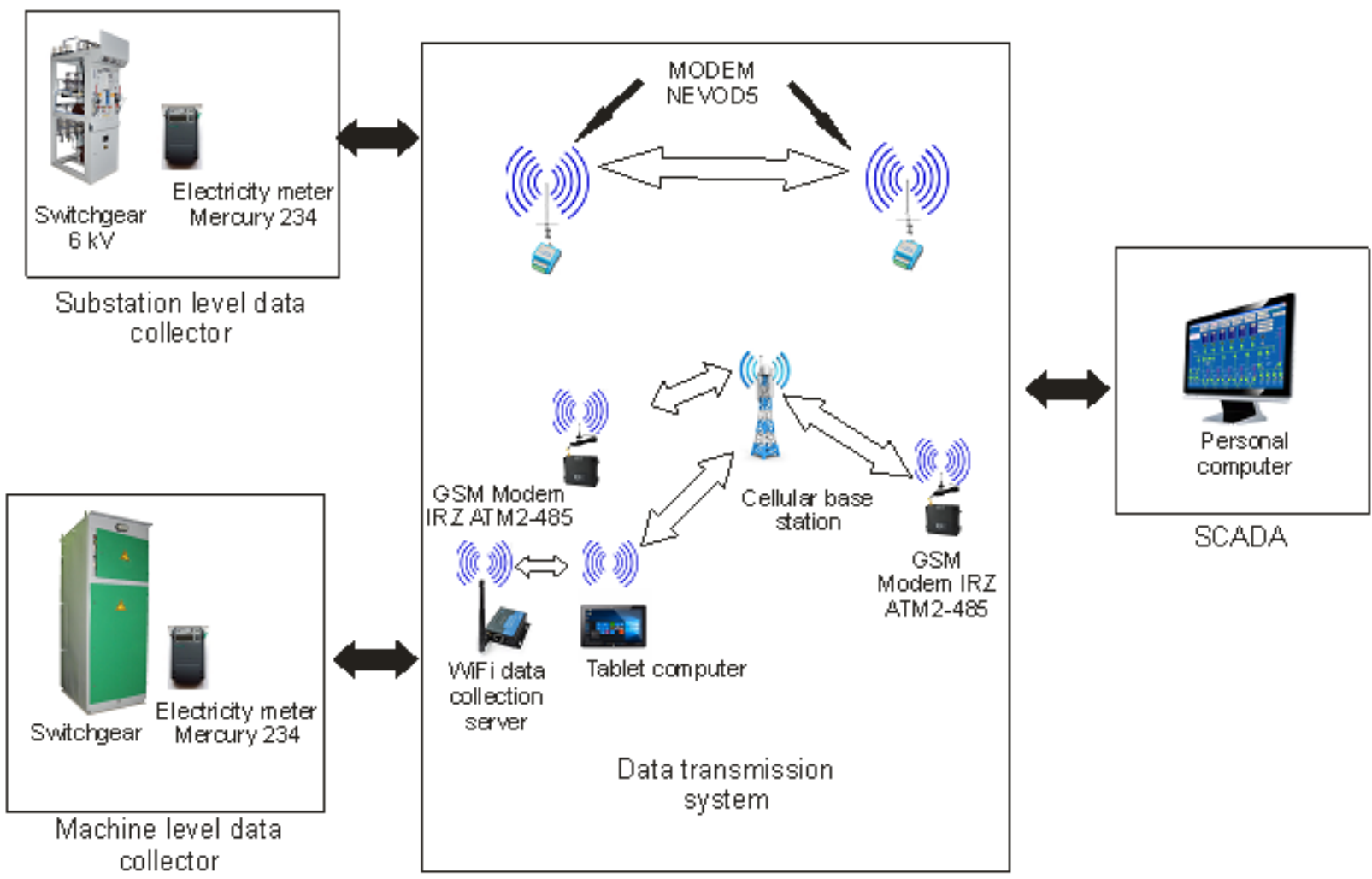

Fig. 1. The structure of telemetry system for remote monitoring of power consumption trends for mining equipment

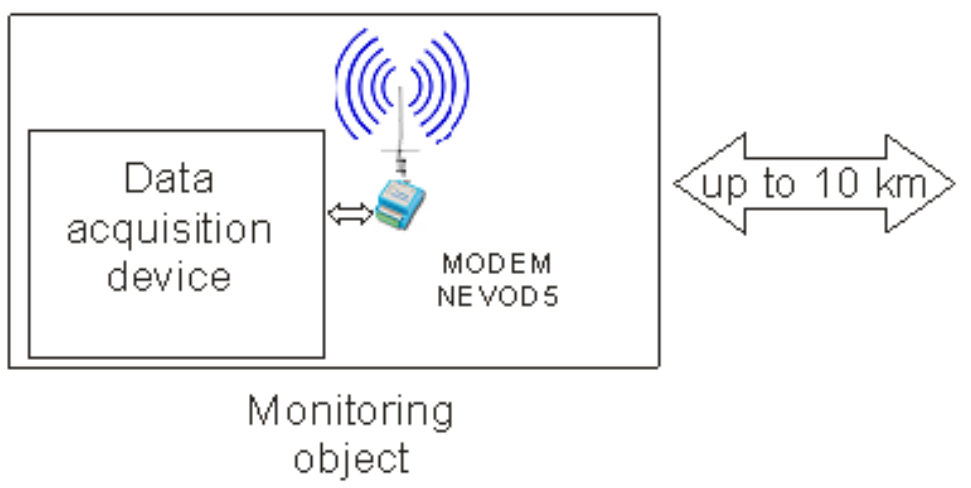

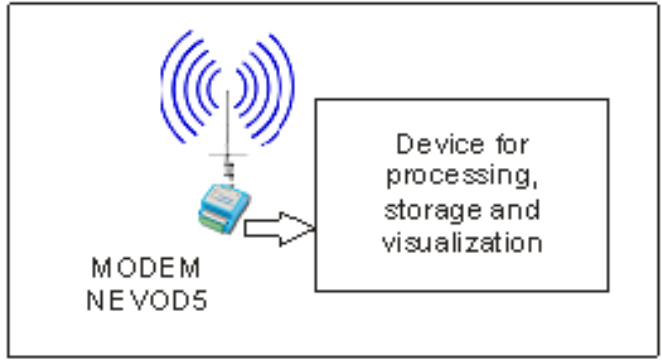

Control room

Fig. 2. Functional diagram of data transmission system using $433 \mathrm{MHz}$ radio channel

This data transmission method is successfully implemented in high voltage substation monitoring system, this system was set up and implemented by the authors of this paper for three high voltage substations, i.e. "Yuzhnaya", "ZapadnayaNovaya" and "Yugo-Zapadnaya" of Shubarkol-Komir JSC open pit coal mine from 2010 to 2012 [6], [7], [8]. [9].

GSM channel was also utilized in data communication systems for remote monitoring of power consumption trends alongside with $433 \mathrm{MHz}$ radio channel. Due to the fact that some of the data acquisition points are located inside the open pit mine at a depth of up to 100 meters the utilization of radio channel was not always possible. In such cases GSM channel can be used as an alternative communication channel if GSM network is available in the area.

There are three main data transmission methods when using wireless GSM technology: using short message service (SMS), GSM voice channel and using general packet radio service (GPRS).

After completing data transmission experiments using GSM communication channel at the open pit mine, all necessary equipment was selected to ensure data transmission stability. Functional diagram of data transmission system using 900 MHz GSM channel is given in Figure 3. GSM channel is utilized for remote monitoring of excavators operating modes at the same Shubarkol-Komir JSC open pit coal mine. In the areas with stable GSM coverage this channel enables realtime monitoring of excavators energy consumption. 


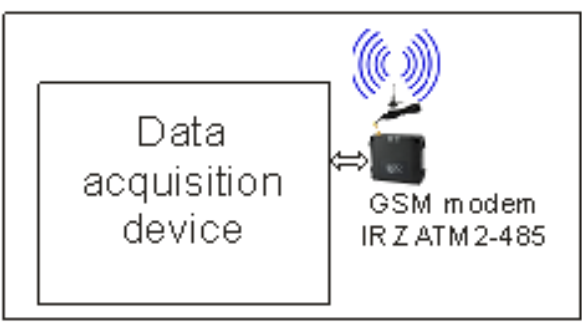

Monitoring object

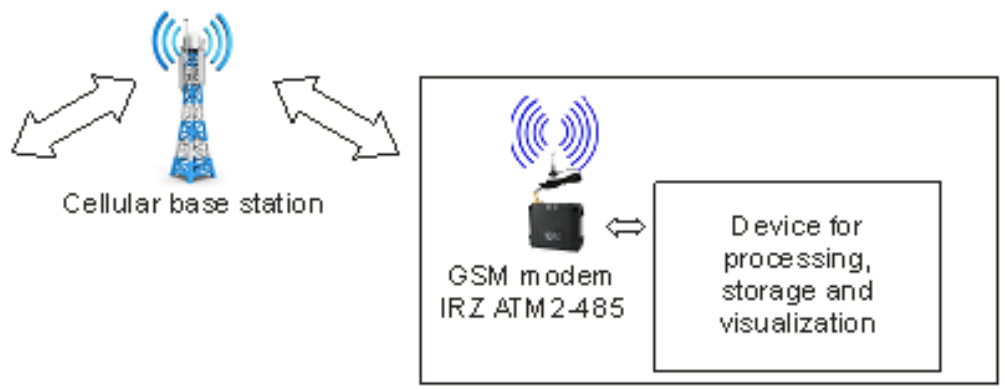

Control room

Fig. 3. Functional diagram of data transmission system using $900 \mathrm{MHz}$ GSM channel

GSM modems IRZ ATM2-485 are used as receiver-transmitter modules. Wireless GSM modems IRZ ATM2-485 enable data transmission in GPRS network using TCP/IP protocol stack. The module is designated for operating in telemetry systems. Modems operate together with double band GSM magnetic base antenna.

After a series of studies on using different types of communication channels were conducted at Shubarkol-Komir JSC open pit coal mine, we have obtained results that allow us to assess the application feasibility of each channel. To ensure continuous operation of data communication system for remote monitoring of power consumption for mining equipment a combination of communication channels should be used, including $433 \mathrm{MHz}$ radio channel, GSM channel and $2.4 \mathrm{MHz}$ Wi-Fi channel. The set up of such system requires these channels to work both in combination and separately. The system will automatically determine which channel is available at the particular moment.

Primary communication channel is different for each open pit mine section. $433 \mathrm{MHz}$ radio channel will be used for units installed on the ground surface level and at a close distance from each other. In case radio communication is not available in bad weather conditions or for any other reasons then communication will be carried out through GSM channel using GPRS [9], [10].

For those units located deeper into the mine and provided that there is GSM coverage GSM channel will serve as a primary communication channel.

The use of a combination of communication channels was suggested and implemented to ensure continuous operation of the system when it was impossible or economically impractical to set up a radio channel. Functional diagram of data transmission system for open pit coal mine using a combination of communication channels is shown in Figure 4.

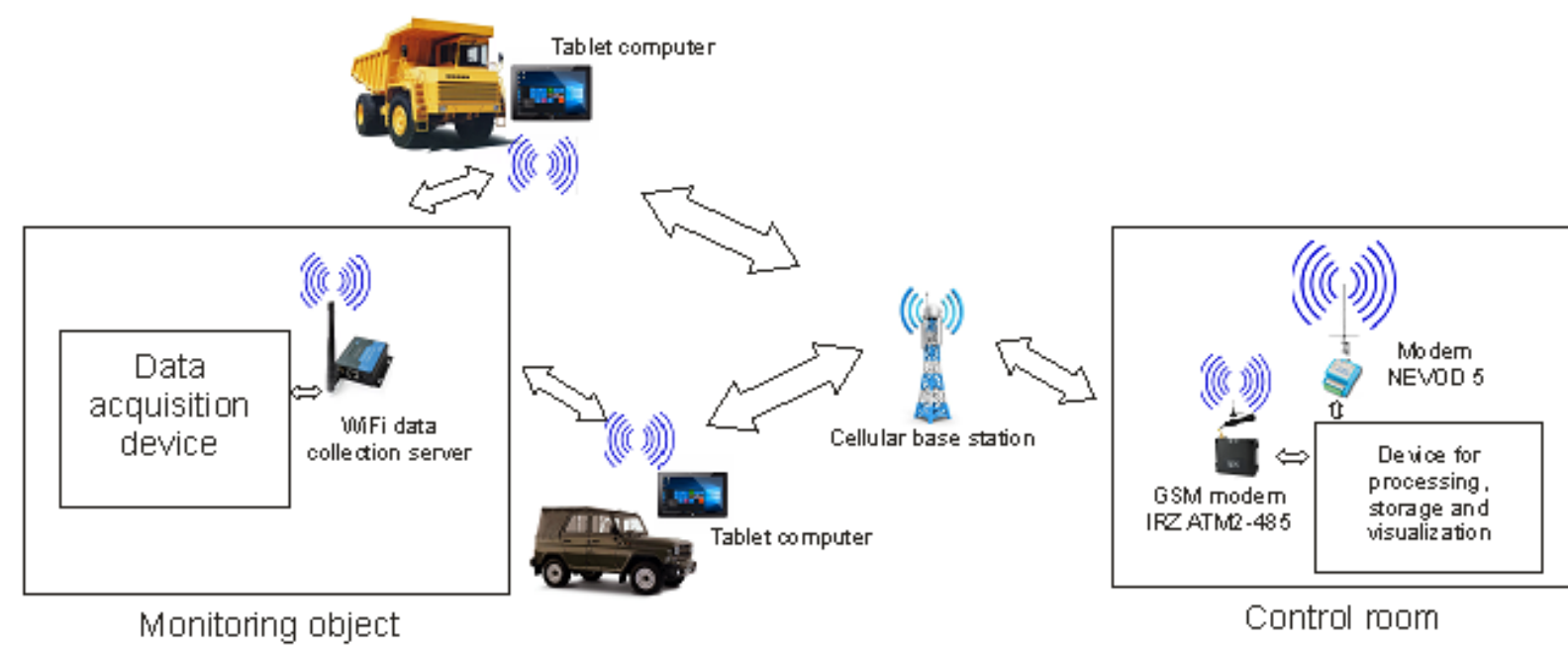

Fig. 4. Functional diagram of data transmission system using a combination of communication channels

The system set up is as follows: the cabin of each vehicle operating on the mine site on day to day basis is equipped with a tablet computer with the appropriate software. When such vehicle comes close to data acquisition point then connection is established and necessary data is automatically transferred. The data is transmitted through Wi-Fi network using the built-in receiver-transmitter in the tablet PC and specially installed modem at the data acquisition point. Tablet PC also detects GSM network availability to transmit accumulated data to control room. When network coverage is not 
available tablet PC provides the possibility to transmit data directly at the control room. Such system enables efficient utilization of communication channels to ensure continuous work of the system.

This method of data transmission is successfully implemented in remote monitoring system for power consumption of six excavators at Shubarkol-Komir JSC open pit coal mine from 2015 to 2018.

\section{Results and discussion of experimental studies}

The analysis of GSM channel connection quality was done as a part of experimental studies and it showed that stable connection was observed with crawler mounted power shovels EKG-12,5 and walking excavators ESH-10/70. This is due to the fact that this machinery when performing stripping works is on the highest level mark. Therefore, these units are within the strong signal zone of cellular base station.

In order to analyze GSM channel connection quality within 24 hours, a random day was chosen for a unit with the most stable connection. Figure 5 shows a chart with hourly analysis of connection quality from walking excavator ESH$10 / 70 \# 2$. As seen from the chart the connection is not always stable within one hour, nevertheless as there is no need for real time monitoring, these signal failures do not affect monitoring quality as the data on energy consumption is collected in order to identify specific energy consumption rates per product unit. To acquire objective data half-hour averaging of readings was used. Also, a number of experiments showed that the signal was completely absent for the excavators working at the bottom of the mine, for this reason the combination of communication channels using tablet computers was set up.

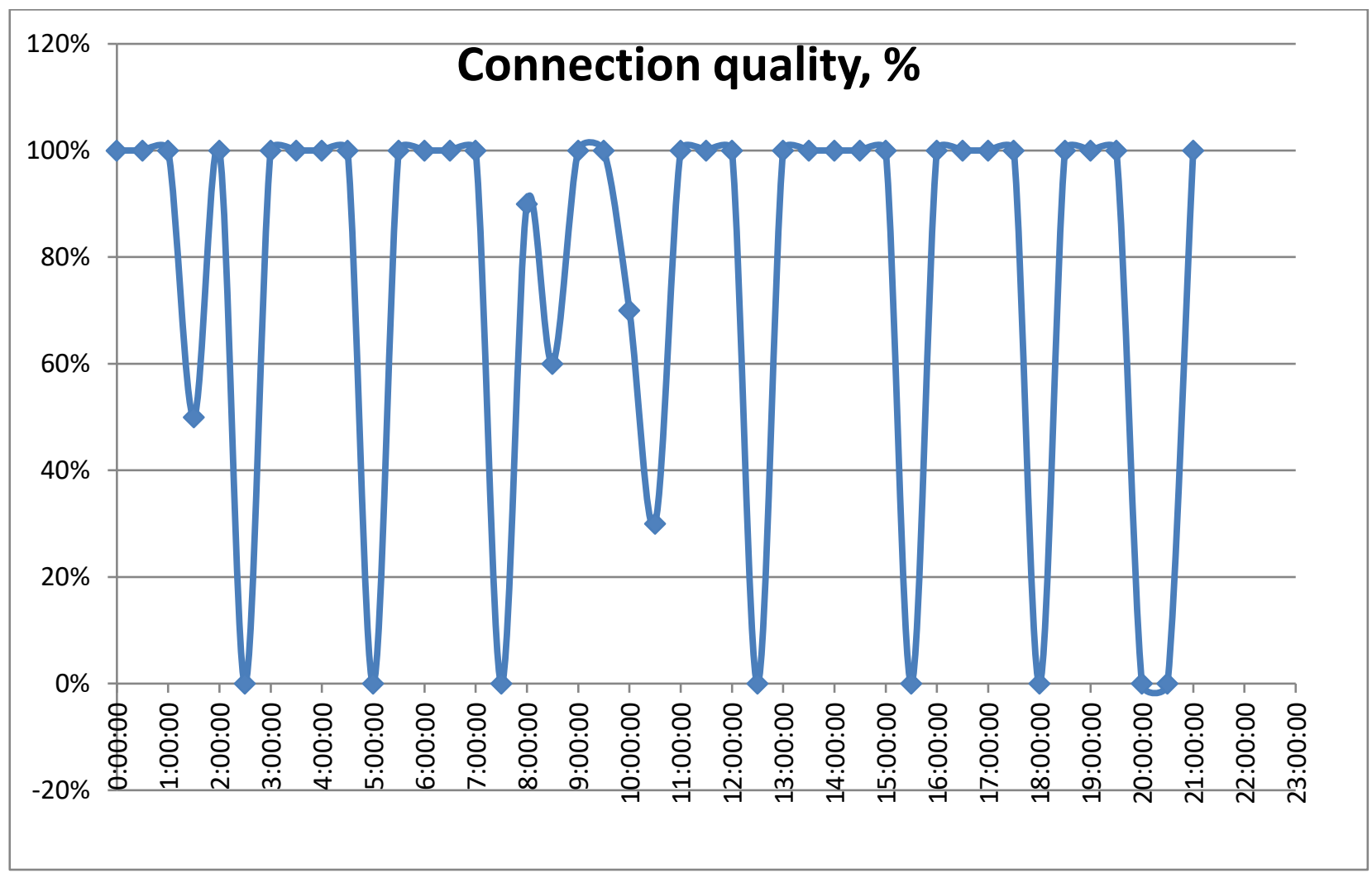

Fig. 5. Hourly analysis of connection quality from walking excavator ESH-10/70

The analysis of the accumulated data shows the efficiency of GSM channel as a data acquisition channel at "Shubarkol-Komir" JSC when connection is reliable. The use of this communication channel is acceptable for the systems that do not require real time monitoring.

In order to analyze radio channel connection quality an experiment was carried out at "Yuzhnaya" substation at "Shubarkol-Komir" JSC open pit mine. The experiment included registering of data on the presence of connection with the control room over a month. The chart on connection presence is given in Figure 6. As seen from the chart, the connection was stable over the month. 


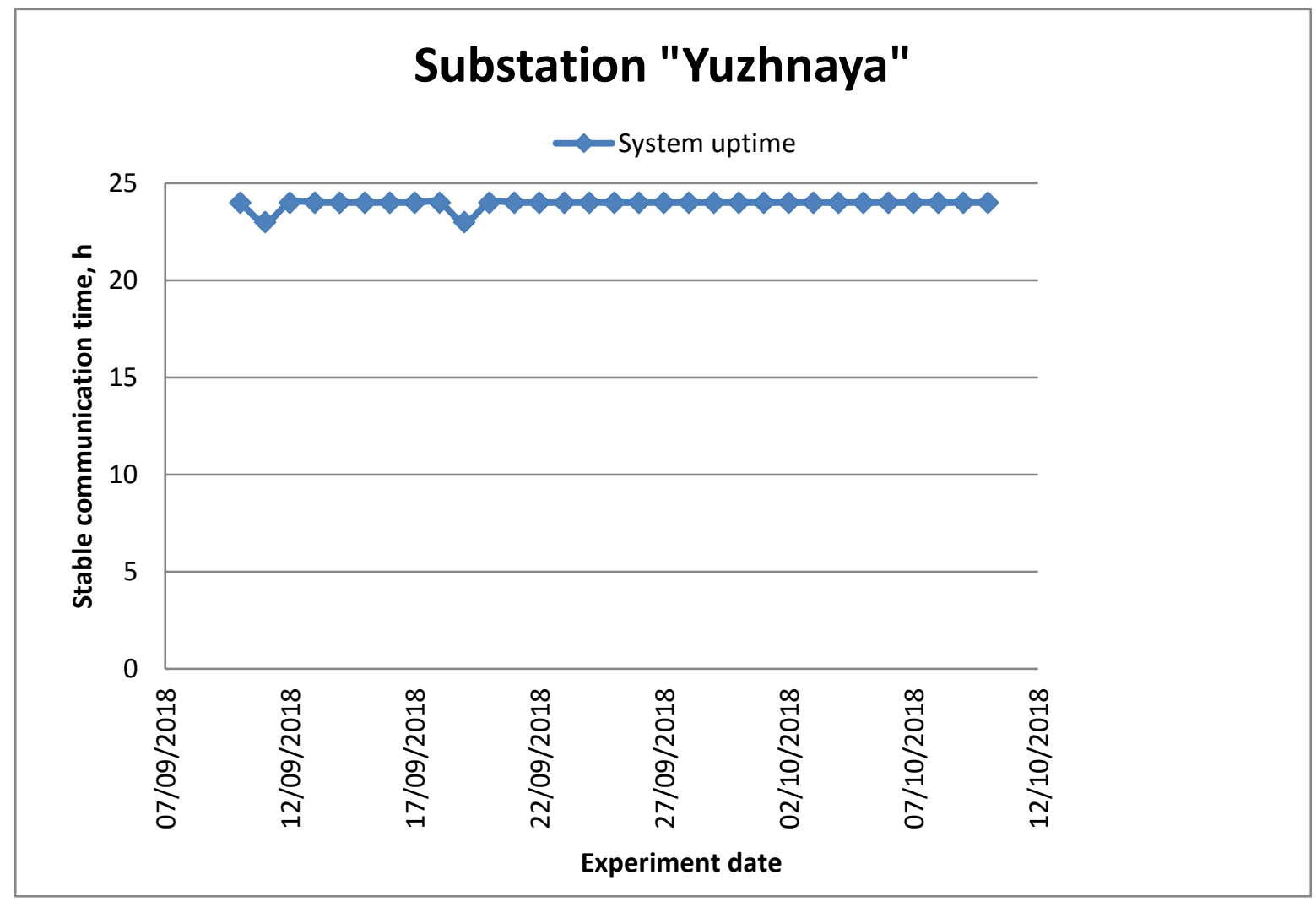

Fig. 6. Monthly analysis of connection quality at "Yuzhnaya" substation

The analysis of connection quality when using radio channel done as a part of experimental studies showed that connection with the substations that are located on the surface is consistently reliable.

\section{Conclusion}

Wireless systems for remote monitoring of power consumption by electric mining equipment enable the companies to efficiently use their existing power resources. A wide range of operating conditions of mining equipment led to such a pressing problem as the absence of clear recommendations on what communication channels should be used for industrial data communication.

In this paper we performed the analysis of the existing communication channels used in remote monitoring systems. The research has shown that the use of radio channel is most practical for production facilities and units located in the direct line of sight or at a close distance from each other. In case radio connection is poor or completely absent then communication is carried out through GSM channel using GPRS technology. It is also possible to use an alternative method of data communication and namely a combination of communication channels and additional equipment. The implementation of combined communication methods and the use of noise immunity systems enables the efficient functioning of wireless systems for remote monitoring of power consumption by electric mining equipment. This leads to continuous process control over remote equipment which in turn results in efficient energy use and production costs optimization.

In the future, it is planned to implement this system at main enterprises in open mining sector in the Republic of Kazakhstan. The implementation of the system will allow monitoring of equipment performance, timely maintenance, immediate detection of equipment malfunctions as well violations of work order by personnel. Also, the system is planned to be upgraded in terms of integration with the existing enterprise databases.

\section{References}

[1] Velikanov, V. (2014). The on-board diagnostic information system as a means to improve the reliability and durability of mining machines // Modern scientific research and innovations. Issue \#10 part 1, Magnitogorsk, Russia

[2] Vas'kov, V. Justification for excavator monitoring system. Ural State Transport University. Yekaterinburg, Russia

[3] Breido, I.; Sichkarenko, A.; Kotov, Y. (2016). Remote monitoring systems for high-voltage substations and mining machines at open pit coal mines. Journal of Mining Science. No. 5 2016. Pages 919-926. ISSN: 1062-7391 (Print) 1573-8736 (Online). Novosibirsk, Russia 
[4] Breido, I.; Sichkarenko, A.; Kotov, Y. (2013). Emergency control of technological environment and electric machinery activity in coal mines. Journal of Mining Science. No. 3 2013. Pages 338-342. ISSN: 1062-7391 (Print) 1573-8736 (Online). Novosibirsk, Russia

[5] Matysek, M [iroslav]; Adamek, M [ilan] \& Karafiat, T [omas] (2015). The Mobile Monitoring and Control of Real Systems, Proceedings of the 26th DAAAM International Symposium, pp.0104- 0108, B. Katalinic (Ed.), Published by DAAAM International, ISBN 978-3-902734-07-5, ISSN 1726- 9679, Vienna, Austria

[6] Breido, I.; Sichkarenko, A.; Kotov, Y.; Kovalskiy A, (2012). Automatic control system for substation operating modes at open pit coal mines. Proceedings of the X International Science and Technology Forum "Innovation, ecology and resource-saving technologies.", 9 - 11 October 2012 - S. . Pages 385-393. Rostov-on-Don, Russia

[7] Belov, O.; Parfenkin, A. (2014). System Integration Of Electrical Equipment Monitoring. . No. 1 Vol. $10,2014$. Pages 14-17. ISSN 1999-5458 Petropavlovsk-Kamchatsky, Russia

[8] Zavyalov, V.; Noskov, A.; Gorodnyanskiy, V.; Gargaev A. (2009) Monitoring System of Dynamic Status of Power Shovels Electric Drives. Electrical equipment and systems. Pages 59-61. Kemerovo, Russia

[9] Breido, I.; Sichkarenko, A.; Kotov, Y.; Kovalskiy A, (2012). Automatic control system for high-voltage substations operating modes at open pit coal mines. Proceedings of the International research to practice conference "Information and telecommunication technologies: education, science and practice", KazNTU named after K.I. Satpayev, 5 - 6 December 2012. Pages 63-66. Almaty, Kazakhstan

[10] Breido, I.; Sichkarenko, A.; Kotov, Y. (2014) Information systems of automatic control of substation modes at open pit coal mines. Proceedings of the International Scientific and Methodological Conference on Information Engineering Education, "Inforino 2014"., 15 - 16.04.2014. - P. Pages 197-198. Moscow, Russia 